\title{
Carbon Monoxide Promotes the Catalytic Hydrogenation on Metal Cluster Catalysts
}

\author{
Ruixuan Qin $\mathbb{D}^{1},{ }^{1}$ Pei Wang, ${ }^{1,2}$ Pengxin Liu ${ }^{D},{ }^{1}$ Shiguang Mo, ${ }^{1}$ Yue Gong ${ }^{D},{ }^{3}$ Liting Ren, ${ }^{1}$ \\ Chaofa Xu $\odot{ }^{1},{ }^{1}$ Kunlong Liu, ${ }^{1}$ Lin Gu $\left(1,{ }^{3}\right.$ Gang Fu $\odot,{ }^{1}$ and Nanfeng Zheng ${ }^{1}{ }^{1}$ \\ ${ }^{1}$ State Key Laboratory for Physical Chemistry of Solid Surfaces, Collaborative Innovation Center of Chemistry for Energy Materials, \\ and National \& Local Joint Engineering Research Center for Preparation Technology of Nanomaterials, College of Chemistry and \\ Chemical Engineering, Xiamen University, Xiamen 361005, China \\ ${ }^{2}$ College of Science, Huazhong Agricultural University, Wuhan 430070, China \\ ${ }^{3}$ Institute of Physics, Chinese Academy of Sciences, Beijing 100190, China
}

Correspondence should be addressed to Gang Fu; gfu@xmu.edu.cn and Nanfeng Zheng; nfzheng@xmu.edu.cn

Received 12 March 2020; Accepted 17 June 2020; Published 17 July 2020

Copyright (C) 2020 Ruixuan Qin et al. Exclusive Licensee Science and Technology Review Publishing House. Distributed under a Creative Commons Attribution License (CC BY 4.0).

\begin{abstract}
Size effect plays a crucial role in catalytic hydrogenation. The highly dispersed ultrasmall clusters with a limited number of metal atoms are one candidate of the next generation catalysts that bridge the single-atom metal catalysts and metal nanoparticles. However, for the unfavorable electronic property and their interaction with the substrates, they usually exhibit sluggish activity. Taking advantage of the small size, their catalytic property would be mediated by surface binding species. The combination of metal cluster coordination chemistry brings new opportunity. $\mathrm{CO}$ poisoning is notorious for Pt group metal catalysts as the strong adsorption of $\mathrm{CO}$ would block the active centers. In this work, we will demonstrate that CO could serve as a promoter for the catalytic hydrogenation when ultrasmall Pd clusters are employed. By means of DFT calculations, we show that $\mathrm{Pd}_{n}(n=2-147)$ clusters display sluggish activity for hydrogenation due to the too strong binding of hydrogen atom and reaction intermediates thereon, whereas introducing $\mathrm{CO}$ would reduce the binding energies of vicinal sites, thus enhancing the hydrogenation reaction. Experimentally, supported $\mathrm{Pd}_{2} \mathrm{CO}$ catalysts are fabricated by depositing preestablished $\left[\mathrm{Pd}_{2}(\mu-\mathrm{CO})_{2} \mathrm{Cl}_{4}\right]^{2-}$ clusters on oxides and demonstrated as an outstanding catalyst for the hydrogenation of styrene. The promoting effect of $\mathrm{CO}$ is further verified experimentally by removing and reintroducing a proper amount of $\mathrm{CO}$ on the Pd cluster catalysts.
\end{abstract}

\section{Introduction}

Metal catalysts are widely used in industrial applications. Metal nanoparticles, clusters, and even atomically dispersed metal catalysts have been extensively explored for their high mass-specific activity [1-5]. For a wide range of reactions on metal surfaces, the adsorption energies and activation barriers are typically related to the Brønsted-Evans-Polanyi relationships [6-8]. As for metal catalysts with different sizes, their coordinative and electronic properties are often different from each other. For example, small metal clusters with a large part of coordinative unsaturated sites usually have stronger interaction energy with molecules than that of their larger counterparts $[9,10]$. According to the Sabatier principle [11], the optimum catalytic performance can be achieved with a medium interaction energy such that volcano-shaped size-performance relationships would be observed in many heterogeneous catalytic reactions [12-16].

In addition to the size effect, the adsorbate-catalyst interaction also causes the electron redistribution in the unity. Similar to the ligands on homogenous catalysts, the coadsorbates on heterogeneous catalysts are able to modulate the electronic and coordinative structures as well, thus altering the adsorption energies of substrates and intermediates [17-21]. These effects will be more profound on ultrasmall clusters where the large ratio of surface atoms makes them an ingenious platform for modulating their electronic properties and thus catalytic performance through the surface coordination chemistry $[22,23]$. 
In this work, through systematic density functional theory (DFT) calculations, we revealed that supported ultrasmall Pd clusters interacted too strongly with $\mathrm{H}$ atoms as well as reaction intermediates such that the hydrogenation activity was inhibited. When electron-withdrawing molecules (e.g., CO) were introduced, the adsorption energies of $\mathrm{H}$ atoms and hydrogenated intermediates on $\mathrm{Pd}$ clusters were weakened, thus boosting hydrogenation performance. Based on the theoretical analysis, oxide-supported $\mathrm{Pd}_{2}$ catalysts with $\mathrm{CO}$ binding were synthesized by using presynthesized carbonyl dipalladium clusters, $\left[\mathrm{Pd}_{2}(\mu-\mathrm{CO})_{2} \mathrm{Cl}_{4}\right]^{2-}$, as the precursor. Indeed, the as-prepared $\mathrm{Pd}_{2} \mathrm{CO}$ catalyst exhibits dramatically enhanced hydrogenation activity. Further experiments revealed that a proper amount of preadsorbed CO showed positive effect for hydrogenation on metal cluster catalysts but negative effect on single-atom catalysts and negligible effect on nanocatalysts. We expected that the metal cluster catalysts with molecular modifiers would have more room to be tuned and bridge the gap of single-atom catalysts and nanosized catalysts.

\section{Results}

It is widely accepted that the hydrogenation of $\mathrm{C}=\mathrm{C}$ bonds follows the so-called Horiuti-Polanyi (H-P) mechanism, which consists of the successive addition of atomic hydrogen to the substrate. In this case, adsorption energies of $\mathrm{H}$ atoms on a metal surface turned out to be a critical descriptor [24-26]. In earlier works, the dissociation adsorption energy $\left(\Delta E_{2 \mathrm{H}}\right)$ of $\mathrm{H}_{2}$ on $\mathrm{Pd}(111)$ and $\mathrm{Pd}(100)$ was calculated to be $-1.08 \mathrm{eV}$ and $-0.98 \mathrm{eV}$, respectively [27-29]. Both the experiment and theoretical calculations showed that hydrogenation of alkenes would occur smoothly on both $\operatorname{Pd}(111)$ and $\operatorname{Pd}(100)$ [30]. In addition, it has also been reported that $\Delta E_{2 \mathrm{H}}$ decreased with the size decrease of Pd nanoparticles [31-33]. In order to calculate the dissociation adsorption energy of $\mathrm{H}_{2}$ on different $\mathrm{Pd}$ clusters, here, we constructed a set of $\mathrm{Pd}_{n}$ with size varying from $\mathrm{Pd}_{2}$ to $\mathrm{Pd}_{147}$. For simplicity, $\mathrm{H}$ atoms were placed on the most favorable sites in neighbor configuration. Figure 1 plots the calculated $\Delta E_{2 \mathrm{H}}$ versus the reciprocal of the size of $\mathrm{Pd}_{n}$ clusters, i.e., $n^{-1 / 3}$. According to our DFT calculations, despite the tortuous trends, $\Delta E_{2 H}$ became much lower than that of $\operatorname{Pd}(111)$ and $\operatorname{Pd}(100)$ following the decreasing size of $\mathrm{Pd}$ clusters. To the extreme cases, $\Delta E_{2 \mathrm{H}}$ for $\mathrm{Pd}_{2}$ and $\mathrm{Pd}_{3}$ clusters were predicted to be as low as $-2.22 \mathrm{eV}$ and $-1.73 \mathrm{eV}$, respectively. Such strong binding of $\mathrm{H}$ atoms indicated that ultrasmall $\mathrm{Pd}_{n}$ clusters would have poor activity towards hydrogenation.

For the practical using, Pd clusters should be loaded on supports such that the support effect on $\Delta E_{2 \mathrm{H}}$ should not be neglected [34-37]. Computationally, $\operatorname{Pd}_{n}(n=2-7)$ clusters were placed on the anatase $\mathrm{TiO}_{2}(010)$ slab surface (Figures S1-S3). DFT calculations demonstrated that the geometries, the Pd-Pd distances, spin states, and the charge distribution of $\mathrm{Pd}_{n}$ clusters changed significantly as compared with their unsupported counterparts (Tables S2$\mathrm{S} 4)$. Unfortunately, upon being supported on oxide, $\Delta E_{2 \mathrm{H}}$ on the $\mathrm{Pd}$ clusters were decreased by $0.2 \sim 0.5 \mathrm{eV}$, further deviating from those of $\operatorname{Pd}(111)$ and $\operatorname{Pd}(100)$. Figure 2

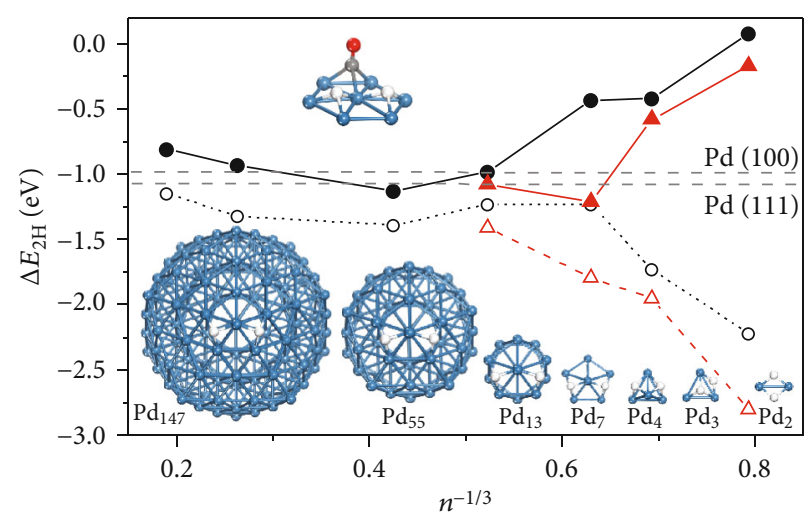

Figure 1: Adsorption energy of $\mathrm{H}_{2}$ on Pd with different sizes. Calculated $\Delta E_{2 \mathrm{H}}$ on bare $\mathrm{Pd}_{n}$ (marked in black circle) and $\mathrm{TiO}_{2}(010)$-supported $\mathrm{Pd}_{n}$ (marked in red triangle) clusters. The hollow and solid symbols are denoted as the CO-free and COmodified cases, respectively. The gray dashed lines represent $\Delta E_{2 \mathrm{H}}$ on $\operatorname{Pd}(111)$ and $\operatorname{Pd}(100)$. The blue, dark gray, red, and white balls represent $\mathrm{Pd}, \mathrm{C}, \mathrm{O}$, and $\mathrm{H}$ atoms. The size of $\mathrm{Pd}$ clusters was estimated by $n^{-1 / 3}$.
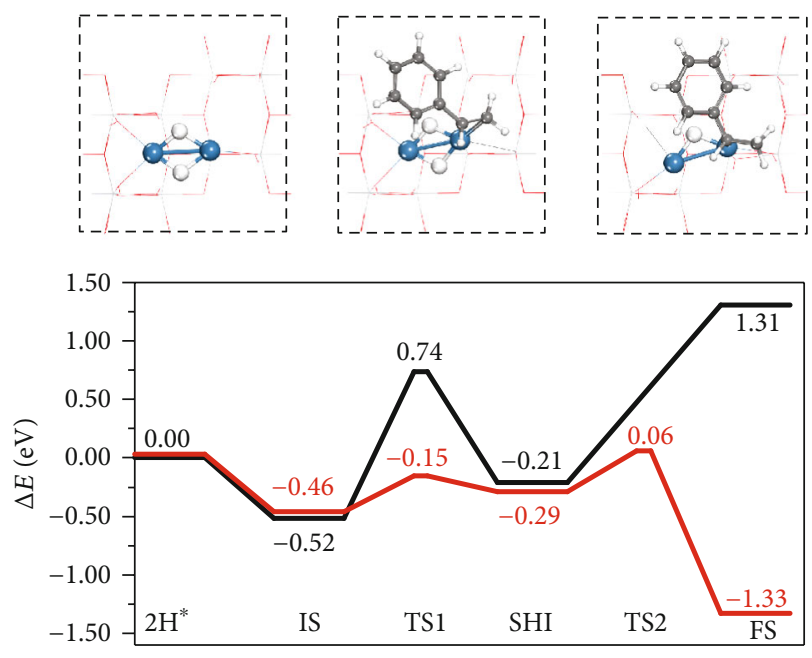

$$
\begin{aligned}
& -\mathrm{Pd}_{2} / \mathrm{TiO}_{2} \\
& -\mathrm{Pd}_{2} \mathrm{CO} / \mathrm{TiO}_{2}
\end{aligned}
$$

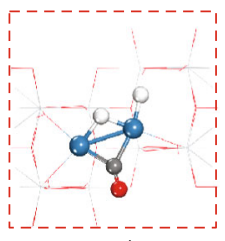

$2 \mathrm{H}^{*}$

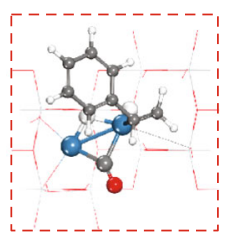

IS

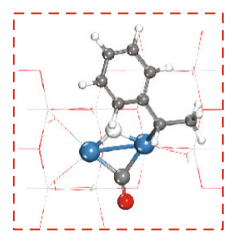

$\mathrm{SH} 1$
FIgURE 2: Theoretical calculation of styrene hydrogenation over $\mathrm{Pd}_{2}$ and $\mathrm{Pd}_{2} \mathrm{CO}$. Energy profiles for styrene hydrogenation on $\mathrm{Pd}_{2} / \mathrm{TiO}_{2}(010)$ (black) and $\mathrm{Pd}_{2} \mathrm{CO} / \mathrm{TiO}_{2}$ (010) (red). IS denoted as the coadsorption of styrene and $\mathrm{H}$ atoms, SHI represented the semihydrogenated intermediate, and FS stood for the gaseous ethylbenzene with the $\mathrm{H}$-free surface. The key structures were illustrated in the black and red dashed frame. The blue, red, dark gray, and white balls represented $\mathrm{Pd}, \mathrm{O}, \mathrm{C}$, and $\mathrm{H}$ atoms, respectively. 
illustrates the calculated energy profile of catalytic hydrogenation of styrene over $\mathrm{TiO}_{2}$-supported $\mathrm{Pd}_{2}$ clusters (denoted as $\mathrm{Pd}_{2} / \mathrm{TiO}_{2}$ ). In the profile, $\mathrm{Pd}_{2}$ with the dissociated $\mathrm{H}$ atoms was used as the energy reference [27]. Styrene was then adsorbed with an adsorption energy of $-0.52 \mathrm{eV}$, close to that on the $\mathrm{H}$-covered $\mathrm{Pd}(100)$ surface $(-0.43 \mathrm{eV})$. However, $\mathrm{Pd}_{2}$ and $\mathrm{Pd}(100)$ have dramatically different behaviors in the following hydrogenation steps. As illustrated in Figure 2, the first step hydrogenation (TS1) on $\mathrm{Pd}_{2} / \mathrm{TiO}_{2}$ involved a barrier of $1.26 \mathrm{eV}$ (Figure S4). More severely, the second step was highly endothermic $(1.52 \mathrm{eV})$, and no TS was able to be located despite our best efforts. These data indicated that not only $\mathrm{H}$ atom but also the alkyl radical was strongly bound on $\mathrm{Pd}_{2} / \mathrm{TiO}_{2}$ [38]. We also explored the hydrogenation of styrene on $\mathrm{TiO}_{2}-$ supported $\mathrm{Pd}_{3}$ clusters $\left(\mathrm{Pd}_{3} / \mathrm{TiO}_{2}\right)$ in which the two-step hydrogenation also exhibited high barriers of $0.70 \mathrm{eV}$ (TS1) and $1.09 \mathrm{eV}$ (TS2) (Figure S5 and S6). All these results suggested that the adsorption of $\mathrm{H}$ atoms and alkyl radical on small $\mathrm{Pd}_{n}$ clusters was too strong, far deviating from the volcano peak based on the Sabatier principle.

The disfavored binding of both $\mathrm{H}$ and alkyl radical is related to the electronic property of the Pd clusters [24, 38]. Thus, a possible way to remedy the hydrogenation activity of $\mathrm{Pd}_{n}$ clusters is to tune their electronic structures. It has been well documented that the adsorbed CO molecules can attract electrons from metal $d$ orbitals [39, 40], thus regulating the adsorption energies of other coadsorbed species [17-21]. In this regard, introducing a proper amount of CO was expected to enhance the catalytic hydrogenation activity of Pd clusters. Computationally, one CO molecule was placed on the site nearby the $\mathrm{H}$ atom adsorption sites, sharing at least one Pd atom (Figures S7-S10). As shown in Figure 1, the presence of $\mathrm{CO}$ did increase $\Delta E_{2 \mathrm{H}}$ on $\mathrm{Pd}$ clusters significantly, especially for those ultrasmall $\mathrm{Pd}_{n}$ clusters $(n=2-7)$. Similarly, the binding energy of styrene on the Pd clsuter was also reduced significantly by the cocoordination of $\mathrm{CO}$ (Figure S11). Inspired by this result, we revisited the catalytic hydrogenation on both $\mathrm{Pd}_{2} / \mathrm{TiO}_{2}$ and $\mathrm{Pd}_{3} / \mathrm{TiO}_{2}$ catalysts with $\mathrm{Pd}$ modified by $\mathrm{CO}$, hereafter denoted as $\mathrm{Pd}_{2} \mathrm{CO} / \mathrm{TiO}_{2}$ and $\mathrm{Pd}_{3} \mathrm{CO} / \mathrm{TiO}_{2}$, respectively. The dissociation of $\mathrm{H}_{2}$ on $\mathrm{Pd}_{2} \mathrm{CO} / \mathrm{TiO}_{2}$ and $\mathrm{Pd}_{3} \mathrm{CO} / \mathrm{TiO}_{2}$ only needs to overcome small barriers of $0.35 \mathrm{eV}$ and $0.18 \mathrm{eV}$ (Figure S10), respectively, indicating that the H-P mechanism would still work on the CO-modified catalysts. As shown in Figure 2, on $\mathrm{Pd}_{2} \mathrm{CO} / \mathrm{TiO}_{2}$, the reaction was downhill by $1.33 \mathrm{eV}$ when going from the $\mathrm{H}$ atom adsorption state to the final state (FS), the production of ethylbenzene. As the result, the stepwise hydrogenation on $\mathrm{Pd}_{2} \mathrm{CO} / \mathrm{TiO}_{2}$ exhibited very small barriers, $0.31 \mathrm{eV}$ (TS1) and $0.35 \mathrm{eV}$ (TS2) (Figure S4). A similar situation was found in $\mathrm{Pd}_{3} \mathrm{CO} / \mathrm{TiO}_{2}$ catalyzed styrene hydrogenation, which was also exothermic by $0.91 \mathrm{eV}$. The calculated barriers for TS1 and TS2 were $0.81 \mathrm{eV}$ and $0.54 \mathrm{eV}$ (Figures S5 and S6), respectively. These findings indicated that introducing a proper amount of $\mathrm{CO}$ on $\mathrm{Pd}_{n}$ clusters would enhance the catalytic hydrogenation.

Inspired by the theoretical results, we synthesized $\mathrm{Pd}_{2} \mathrm{CO} / \mathrm{TiO}_{2}$ by depositing a premade dipalladium complex,
$\left[\mathrm{Pd}_{2}(\mu-\mathrm{CO})_{2} \mathrm{Cl}_{4}\right]^{2-}$, on $\mathrm{TiO}_{2}[41,42]$. The THF solution of the metal precursor was added dropwise into the THF dispersion of $\mathrm{TiO}_{2}$ (Figures S12-S15) with ca. $0.2 \mathrm{wt} \% \mathrm{Pd}$ loading. The scanning transmission electron microscope (STEM) energy dispersive X-ray (EDX) element mapping images in Figure S16 confirmed the highly dispersed Pd on $\mathrm{TiO}_{2}$, and no Pd nanoparticles were observed by HRTEM (Figure S17). As shown in Figure S18, the similar UV-vis spectrum of the as-obtained catalyst to that of the precursor in THF implied the mainly preserved coordination structure of the dinuclear $\mathrm{Pd}_{2}$ motifs. Indeed, high-angle annular dark-field (HAADF) STEM studies (Figure 3(a) and Figure S19) clearly revealed the dinuclear nature of $\mathrm{Pd}$ on $\mathrm{TiO}_{2}$, confirming that the main structure of the dinuclear $\mathrm{Pd}_{2}$ motifs was preserved upon deposition. The measured distance between the two nearby Pd atoms was about $2.7 \AA$, also consistent with that in the corresponding crystal structure (Figure S20 and Tables S5 and S6) and our calculations $(2.72 \AA$, Table S2). As shown in the Fourier transform extended X-ray absorption fine structure (FTEXAFS) in Figure 3(b), the Pd-Pd scattering shell was kept after loading. The fitted coordination number $(\mathrm{CN})$ of $\mathrm{Pd}-$ $\mathrm{Pd}$ in the as-obtained $\mathrm{Pd}_{2} \mathrm{CO} / \mathrm{TiO}_{2}$ was 1.2 , close to that in the precursor (Figures S21 and S22, Table S7). We thus assumed that upon deposition, the $\left[\mathrm{Pd}_{2}(\mu-\mathrm{CO})_{2} \mathrm{Cl}_{4}\right]^{2-}$ cluster reacted with the surface-adsorbed water or hydroxyl species with one of the $\mathrm{CO}$ ligands oxidized into $\mathrm{CO}_{2}$ (see Equation (1)), while the other $\mathrm{CO}$ remained on the deposited Pd cluster [43]. The retained CO was confirmed by DRIFTS and temperature programmed desorption-mass spectrometry (TPD-MS) (Figures S23-S25):

$\left[\mathrm{Pd}_{2}(\mu-\mathrm{CO})_{2} \mathrm{Cl}_{4}\right]^{2-}+\mathrm{H}_{2} \mathrm{O} \rightarrow \mathrm{Pd}_{2}(\mu-\mathrm{CO})+\mathrm{CO}_{2}+2 \mathrm{H}^{+}+4 \mathrm{Cl}^{-}$

As shown in the diffuse reflectance infrared Fourier transform spectroscopy (DRIFTS) for $\mathrm{Pd}_{2} \mathrm{CO} / \mathrm{TiO}_{2}$ catalyzed ethylene hydrogenation (Figure S26), the $\mathrm{CO}$ molecules inherited from the carbonyl precursors were nicely preserved on $\mathrm{Pd}$. The catalytic activity of $\mathrm{Pd}_{2} \mathrm{CO} / \mathrm{TiO}_{2}$ in the hydrogenation of styrene was evaluated and compared with those of single-atom Pd catalysts, such as $\mathrm{Pd}_{1} / \mathrm{TiO}_{2}$-EG (denoted as $\mathrm{Pd}_{1}$ ) with single-atom $\mathrm{Pd}$ on ethylene glycolate-stabilized $\mathrm{TiO}_{2}(\mathrm{~B})$ [43], and $\mathrm{Pd}_{1} / \mathrm{TiO}_{2}$-cal (denoted as $\mathrm{Pd}_{1}$-cal) with surface ethylene glycolate removed by calcination [44]. As shown in Figure 3(c), $\mathrm{Pd}_{2} \mathrm{CO} / \mathrm{TiO}_{2}$ exhibited a much higher activity than the two single-atom $\mathrm{Pd}$ catalysts $[45,46]$. The calculated TOFs based on the surface Pd atoms (Figure S27) revealed that, with the presence of $\mathrm{CO}$ binding, the supported $\mathrm{Pd}_{2}$ clusters were indeed as active as the surface $\mathrm{Pd}$ on large NPs. More importantly, the high Pd dispersion made the supported $\mathrm{Pd}_{2} \mathrm{CO}$ exhibit several times higher mass-specific activity (normalized by all $\mathrm{Pd}$ atoms in the catalyst). In addition, as shown in Figure 3(d), the apparent activation energy $\left(E_{\mathrm{a}}\right)$ of $\mathrm{Pd}_{2} \mathrm{CO} / \mathrm{TiO}_{2}(29.6 \mathrm{~kJ} / \mathrm{mol})$ was much smaller than the single-atom $\mathrm{Pd}$ catalysts $\left(\mathrm{Pd}_{1}, 57.9 \mathrm{~kJ} / \mathrm{mol} ; \mathrm{Pd}_{1}\right.$-cal, $112.7 \mathrm{~kJ} / \mathrm{mol}$ ) and comparable to that of $\mathrm{Pd}$ nanosheets 


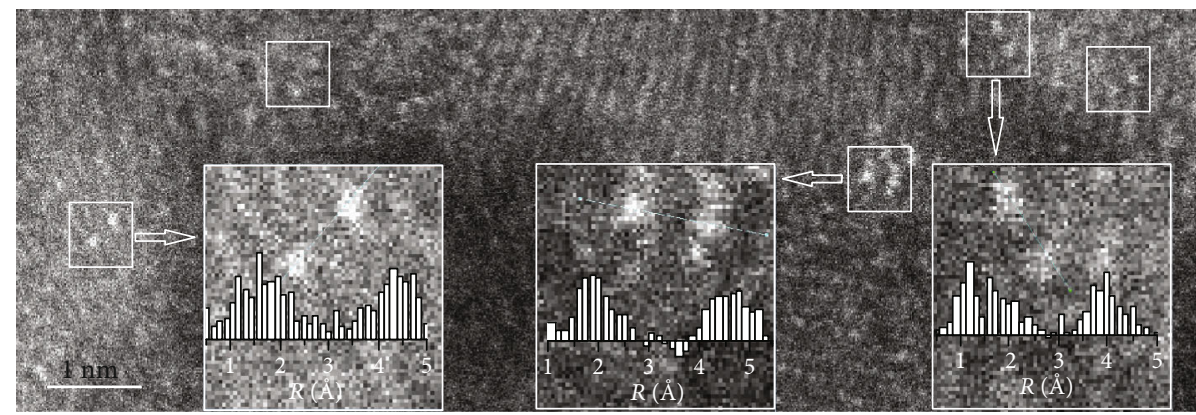

(a)

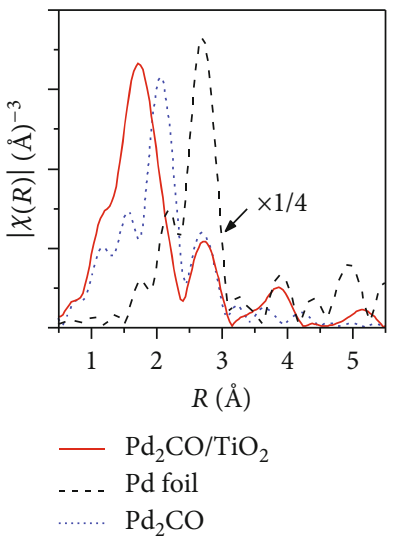

(b)

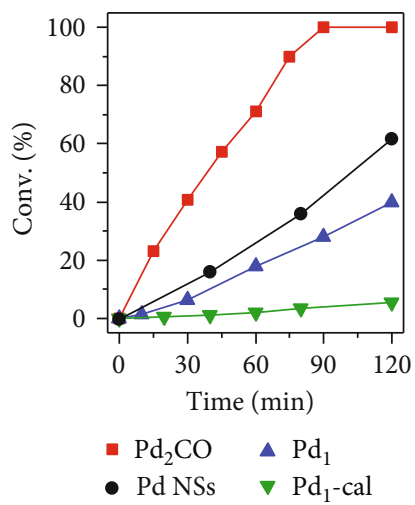

(c)

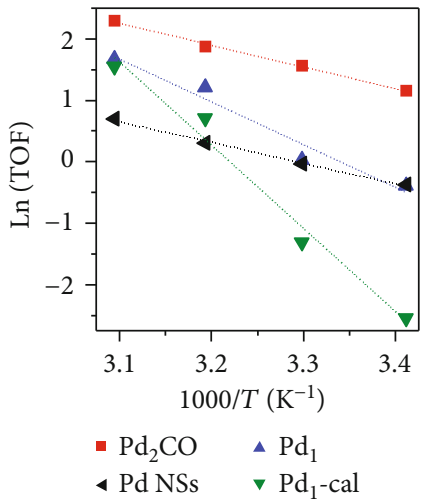

(d)

FIGURE 3: Structure characterization and styrene hydrogenation performance. (a) HAADF-STEM images of $\mathrm{Pd}_{2} \mathrm{CO} / \mathrm{TiO}_{2}$. The three inserted images demonstrated the distances between two palladium atoms. (b) FT-EXAFS of $\mathrm{Pd}_{2} \mathrm{CO} / \mathrm{TiO}_{2}$, palladium foil, and the $\mathrm{Pd} \mathrm{C}_{2} \mathrm{CO}$, $\left(\mathrm{PPh}_{4}\right)_{2}\left[\mathrm{Pd}_{2}(\mu-\mathrm{CO})_{2} \mathrm{Cl}_{4}\right]$. (c) Styrene conversion profiles and (d) corresponding Arrhenius plots of $\mathrm{Pd}_{2} \mathrm{CO} / \mathrm{TiO}_{2}\left(\mathrm{Pd}_{2} \mathrm{CO}\right), \mathrm{Pd}$ nanosheets (Pd NSs), $\mathrm{Pd}_{1} / \mathrm{TiO}_{2}$-EG $\left(\mathrm{Pd}_{1}\right), \mathrm{Pd}_{1} / \mathrm{TiO}_{2}$-cal $\left(\mathrm{Pd}_{1}\right.$-cal$)$.

$(28.2 \mathrm{~kJ} / \mathrm{mol})$. Furthermore, when $\mathrm{D}_{2}$ was used to replace $\mathrm{H}_{2}$ for the catalysis (Figure S28), a normal isotope effect of 2.02 was observed on $\mathrm{Pd}_{2} \mathrm{CO} / \mathrm{TiO}_{2}$, confirming the homolytic activation mechanism of $\mathrm{H}_{2}$. Although the Pd$\mathrm{Pd}$ coordination number was slightly changed (Figure S29, Table S7), $\mathrm{Pd}_{2} \mathrm{CO} / \mathrm{TiO}_{2}$ maintained its high catalytic activity in 5 runs (Figure S30).

The promotional effect of $\mathrm{CO}$ on $\mathrm{Pd}$ clusters was further confirmed by removing $\mathrm{CO}$ from $\mathrm{Pd}_{2} \mathrm{CO} / \mathrm{TiO}_{2}$ through calcination and readding an appropriate amount of $\mathrm{CO}$ to $\mathrm{CO}$ removal catalysts. The presence of $\mathrm{Pd}-\mathrm{Pd}$ scattering $(\mathrm{CN} \approx 4)$ in FT-EXAFS indicated the formation of larger Pd clusters (ca. a cluster with $\sim 10-20 \mathrm{Pd}$ atoms in average) after calcination and treatment with $\mathrm{H}_{2}$. After reintroducing $\mathrm{CO}$, the bridge site and hollow site $\mathrm{CO}$ adsorbed on reduced Pd were also figured out in DRIFTS (Figure S31). Although no significant structure change of Pd clusters was observed in the FT-EXAFS, the slightly positive shift of XANES after introducing $\mathrm{CO}$ revealed the electronic transfer between the Pd clusters and CO (Figure S32 and Table S7). In styrene hydrogenation, the catalytic activity of $\mathrm{Pd}_{2} / \mathrm{TiO}_{2}$-cal was only $\sim 1 / 5$ of $\mathrm{Pd}_{2} \mathrm{CO} / \mathrm{TiO}_{2}$ (Figure 4 (a) and Figure S26). The apparent activation energy $(80.1 \mathrm{~kJ} / \mathrm{mol}$, Figure S33) was much larger than that of $\mathrm{Pd}_{2} \mathrm{CO} / \mathrm{TiO}_{2}$ and $\mathrm{Pd}$ nanosheets, implying that the bare Pd clusters were not efficient for hydrogenation, also echoing with our theoretical predictions.
Interestingly, by introducing a proper amount of $\mathrm{CO}$ back to the CO-free system, the hydrogenation activity was enhanced by about twice (Figure 4(a)). In comparison, the activity of single-atom $\mathrm{Pd}$ catalysts was deterred significantly upon the introduction of $\mathrm{CO}$, no matter for the calcined and uncalcined samples (Figure 4(b) and Figure S34a). It has been reported that the coordinated CO on the single-atom Ir could promote $\mathrm{CO}$ oxidation following the Eley-Rideal mechanism at the interfacial site [47], but the strongly coordinated $\mathrm{CO}$ on single-atom Pd will block the activation of $\mathrm{H}_{2}$ and inhibit the hydrogenation following the $\mathrm{H}-\mathrm{P}$ mechanism. Interestingly, when $\mathrm{Pd}$ nanosheets and $\mathrm{Pd}$ nanocubes were used, the addition of $\mathrm{CO}$ would not retard much the hydrogenation (Figure 4(c) and Figure S34b). This can be explained by the possible formation of $\mathrm{Pd}$ hydride species upon the introduction of $\mathrm{H}_{2}$, which helps to weaken the CO binding on $\mathrm{Pd}$ and thus exhibits high CO tolerance [48]. Experimentally, the catalytic performance tests were conducted after long-time purging with $\mathrm{H}_{2}$, also helping to remove $\mathrm{CO}$ from the Pd surface.

More impressively, an $\mathrm{Al}_{2} \mathrm{O}_{3}$-supported $\mathrm{Pd}$ catalyst with $0.5 \mathrm{wt} \%$ mass loading and $\sim 55 \% \mathrm{Pd}$ dispersion was prepared (ca. $\sim 1 \mathrm{~nm}, \sim 40 \mathrm{Pd}$ atoms, Figures S35 and 36). The predominant $\mathrm{H}_{2}$ desorption temperature was decreased from about $175^{\circ} \mathrm{C}$ to $120^{\circ} \mathrm{C}$ with preadsorbed $\mathrm{CO}$ (Figure S37), verifying that the adsorption of $\mathrm{CO}$ reduced 


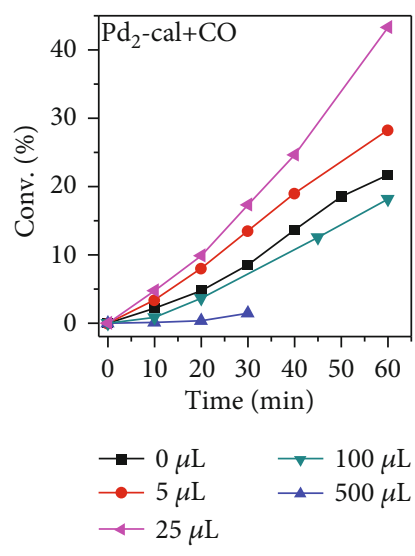

(a)

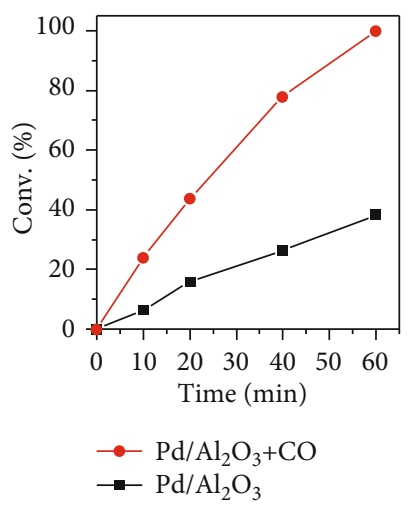

(d)

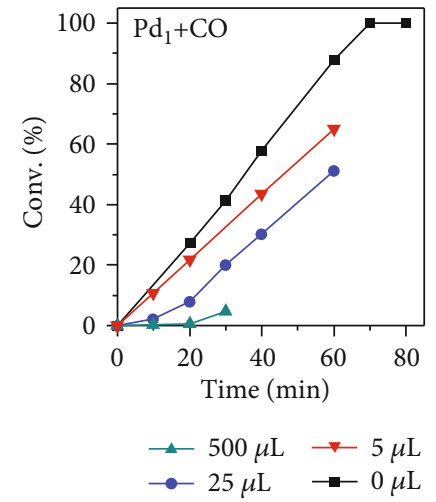

(b)

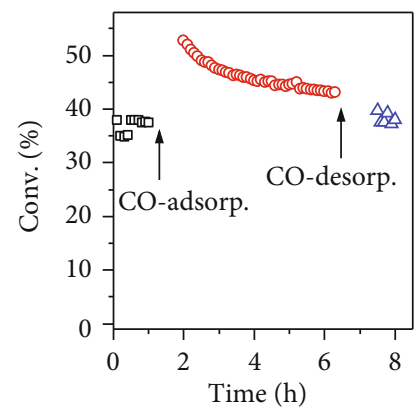

(e)

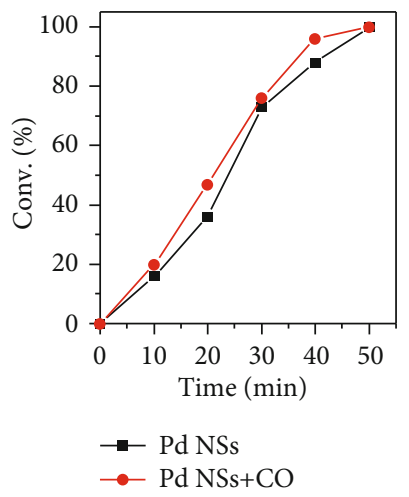

(c)

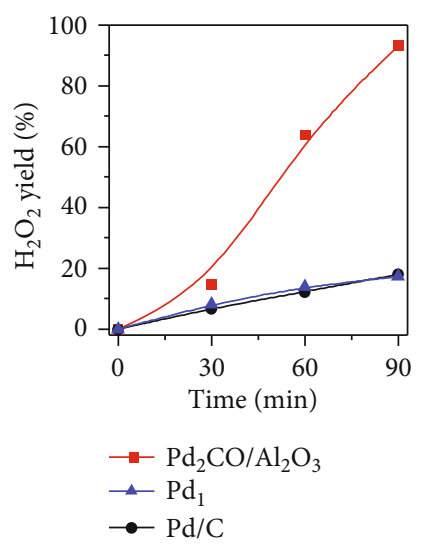

(f)

FIGURE 4: Effect of CO over different Pd catalysts. (a, b) Catalytic styrene hydrogenation performance of $\mathrm{Pd}_{2} / \mathrm{TiO}_{2}$-cal $(S / C=50,000)$ and $\mathrm{Pd}_{1} / \mathrm{TiO}_{2}(\mathrm{~S} / \mathrm{C}=10,000)$ with different amounts of $\mathrm{CO}$ introduced. (c, d) Catalytic styrene hydrogenation performance of $\mathrm{Pd}$ cubes and $0.5 \mathrm{wt} \% \mathrm{Pd} / \mathrm{Al}_{2} \mathrm{O}_{3}(\mathrm{~S} / \mathrm{C}=10,000)$ before and after treatment with $\mathrm{CO}$ (e) The steady state $\mathrm{C}_{2} \mathrm{H}_{4}$ hydrogenation test catalyzed by $0.5 \mathrm{wt} \%$ $\mathrm{Pd} / \mathrm{Al}_{2} \mathrm{O}_{3}$ at $30^{\circ} \mathrm{C}$. (f) $\mathrm{H}_{2} \mathrm{O}_{2}$ yield following the 2-eAQ hydrogenation route catalyzed by $\mathrm{Pd}_{2} \mathrm{CO} / \mathrm{Al}_{2} \mathrm{O}_{3}, \mathrm{Pd}_{1} / \mathrm{TiO}_{2}-\mathrm{EG}$, and $\mathrm{Pd} / \mathrm{C}$.

the binding energy of $\mathrm{H}$ over Pd clusters. Again, in styrene hydrogenation, $0.5 \mathrm{wt} \% \mathrm{Pd} / \mathrm{Al}_{2} \mathrm{O}_{3}$ displayed a three-time enhancement in the catalytic activity after being treated with CO (Figure 4(d)). Furthermore, as demonstrated in the in situ DRIFTS (Figure S38), the adsorbed bridge and hollow site $\mathrm{CO}$ on the reduced Pd surface was preserved on $\mathrm{Pd} / \mathrm{Al}_{2} \mathrm{O}_{3}$ even after being heated up to $100^{\circ} \mathrm{C}$ in the condition of catalytic ethylene hydrogenation. Consequently, as shown in Figure 4(e), after the $\mathrm{Pd} / \mathrm{Al}_{2} \mathrm{O}_{3}$ catalyst was treated with $\mathrm{CO}$, the promotional effect kept for several hours, despite the gradual reduction of the promotional effect related to the desorption of partial $\mathrm{CO}$ during the exothermic ethylene hydrogenation. Once $\mathrm{CO}$ was removed, the activity decreased back to the initial value, excluding the probable structure change.

To expand the applications of the supported $\mathrm{Pd}_{2} \mathrm{CO}$ cluster, $0.2 \mathrm{wt} \% \mathrm{Pd}_{2} \mathrm{CO} / \mathrm{Al}_{2} \mathrm{O}_{3}$ was also fabricated using $\mathrm{Al}_{2} \mathrm{O}_{3}$ as the support (Figures S39 and S40 and Table S7). $\mathrm{Pd}_{2} \mathrm{CO} / \mathrm{Al}_{2} \mathrm{O}_{3}$ exhibited almost the same catalytic activity as $\mathrm{Pd}_{2} \mathrm{CO} / \mathrm{TiO}_{2}$ in styrene hydrogenation (Figure S41), indicating that it was the $\mathrm{CO}$ ligand but not the support promoting the catalysis of the Pd clusters. As demonstrated in the $\mathrm{H}_{2} \mathrm{O}_{2}$ production through the 2-ethylanthraquinone route in Figure $4(\mathrm{f}), \mathrm{Pd}_{2} \mathrm{CO} / \mathrm{Al}_{2} \mathrm{O}_{3}$ was much more efficient than the atomically dispersed $\mathrm{Pd}_{1} / \mathrm{TiO}_{2}$-EG catalyst and also commercial $\mathrm{Pd} / \mathrm{C}$. The $\mathrm{H}_{2} \mathrm{O}_{2}$ yield on $\mathrm{Pd}_{2} \mathrm{CO} / \mathrm{Al}_{2} \mathrm{O}_{3}$ was achieved as high as $93 \%$ with the production rate of $1054 \mathrm{~g}_{\mathrm{H}_{2} \mathrm{O}_{2}} \cdot \mathrm{g}_{\mathrm{Pd}}^{-1} \cdot \mathrm{h}^{-1}($ Table S8).

\section{Discussion}

To summarize, we demonstrate here that the coordination of small molecules on the ultrasmall metal clusters provides a powerful vector in tailoring their catalytic performance. For $\mathrm{Pd}$ clusters with a limited number of $\mathrm{Pd}$ atoms, such as $\mathrm{Pd}_{2}$ and $\mathrm{Pd}_{3}$, the too strong adsorption of the $\mathrm{H}$ atoms and alkyl radicals would inhibit the catalytic hydrogenation. Theoretical calculations predicted that hydrogenation activity would be significantly enhanced by introducing electronwithdrawing molecules, such as $\mathrm{CO}$, on Pd clusters as the adsorption energies of hydrogen and hydrogenated intermediates were reduced. Supported $\mathrm{Pd}_{2} \mathrm{CO}$ clusters were successfully synthesized using dinuclear Pd-carbonyl clusters as the Pd precursor. Surprisingly, the mass-specific activity of supported $\mathrm{Pd}_{2} \mathrm{CO}$ exceeded those of the atomically dispersed Pd catalysts and Pd nanoparticles. The promotion effect of $\mathrm{CO}$ of the catalysis of small Pd clusters was unambiguously 
confirmed by removing and reintroducing CO. Our work reveals that the electronic and coordinative structures of metal clusters are significantly distinguished from those of the conventional metal nanoparticles.

\section{Materials and Methods}

Spin-polarized calculations were carried out with the Vienna ab initio simulation package (VASP) $[49,50]$. The electron exchange and correlation were treated with the generalized gradient approximation using PBE functional [51]. The valence electrons were described by plane wave basis sets with a cut-off energy of $400 \mathrm{eV}$, and the core electrons were replaced by the projector augmented wave pseudopotential $[52,53]$. Geometries of minima and TSs were converged to a residual force smaller than $0.03 \mathrm{eV} / \AA$. The transition states were determined using the nudged elastic band (NEB) approach [54], with a subsequent quasi-Newton optimization to refine the TS' structures and energies. All the local minima and TSs were verified by vibrational frequency calculations.

For $\mathrm{Pd}_{n}$ clusters $(n=2,3,4,7,13,55$, and 147$)$, as shown in Figure 1, the geometry structures with the highest symmetry were chosen $[31,55]$. To avoid image interaction, the shortest distances between the image clusters were set to be more than $10 \AA$. In these cases, the Gamma point only calculations were performed. For the $\operatorname{Pd}(111)$ and $\operatorname{Pd}(100)$ surfaces, $(3 \times 4)$ supercells with five atomic layers were used. The vacuum regions between the slabs were $15 \AA$, and the $k$ -point sampling was generated following the MonkhorstPack procedure with a $3 \times 3 \times 1$ mesh. For the Pd surface models, the bottom two layers were fixed at a bulk truncated position, while the top three layers and the adsorbates were fully relaxed. For the Pd clusters on anatase, a five-layer $\mathrm{TiO}_{2}(010) p(1 \times 4)$ slab was used and the utermost surface was fully hydroxylated (Figure S1). The GGA $+U$ approximation with the Dudarev " $+U$ " term with a $U-J$ value of $4.2 \mathrm{eV}$ for the $\mathrm{d}$ electrons of $\mathrm{Ti}$ atoms was adopted [56]. The structure of anatase-supported $\mathrm{Pd}_{n}$ was optimized by placing different initial configurations of Pd clusters on the surface. Such a method is appropriate to locate the global minima of ultrasmall clusters and has been frequently adopted in the literature [57, 58]. DFT calculations showed that not only the $\mathrm{Pd}_{n}$ cluster but also $\mathrm{Pd}_{n} \mathrm{CO}$ clusters $(n=2-7)$ can strongly interact with the surface oxygen atoms over $\mathrm{TiO}_{2}(010)$.

For the preparation of $\mathrm{Pd}_{2} \mathrm{CO} / \mathrm{TiO}_{2}$, and $\mathrm{Pd}_{2} \mathrm{CO} / \mathrm{Al}_{2} \mathrm{O}_{3}$, $10 \mu \mathrm{L} \mathrm{H}_{2} \mathrm{PdCl}_{4}(1 \mathrm{M})$ was introduced into $1 \mathrm{~mL}$ THF in a glass bottle, and the solution was kept stirred under $0.2 \mathrm{MPa} \mathrm{CO}$ at room temperature till the color of the solution turned into bright yellow. Then, the solution was introduced dropwise into $20 \mathrm{~mL}$ THF dispersions of the supports (500 $\mathrm{mg} \mathrm{TiO}_{2}$ or $\mathrm{Al}_{2} \mathrm{O}_{3}$ ) under stirring; then, the solvent was removed by centrifugation and dried under vacuum at room temperature; the as-obtained catalysts were denoted as $\mathrm{Pd}_{2} \mathrm{CO} / \mathrm{TiO}_{2}$ and $\mathrm{Pd}_{2} \mathrm{CO} / \mathrm{Al}_{2} \mathrm{O}_{3}$. The single-atom Pd catalysts were synthesized following the procedures reported previously $[43,44]$. The colloidal Pd nanosheets (Pd NSs) and Pd nanocubes (Pd NCs) with preferential (111) and (100) exposed surface, respectively, were prepared following the procedures reported previously in our group [27, 41]. All these catalysts were used without any pretreatment. The $0.5 \mathrm{wt} \% \mathrm{Pd} / \mathrm{Al}_{2} \mathrm{O}_{3}$ was prepared following the typical impregnation method; the catalyst was calcined in air at $300^{\circ} \mathrm{C}$ for $2 \mathrm{~h}$ and reduced in $\mathrm{H}_{2}$ at $100^{\circ} \mathrm{C}$ for $1 \mathrm{~h}$ before applying in catalysis. The bridge site and hollow site $\mathrm{CO}$ adsorbed on $0.5 \mathrm{wt} \% \mathrm{Pd} / \mathrm{Al}_{2} \mathrm{O}_{3}$ after reduction suggested the presence of reduced Pd and Pd-Pd moieties on the surface.

For styrene hydrogenation, a proper amount of catalyst was introduced in $10 \mathrm{~mL} \mathrm{EtOH}$ and stirred at $30^{\circ} \mathrm{C}$ and $0.1 \mathrm{MPa}_{2}$ atmosphere for $10 \mathrm{~min}$; then, $0.55 \mathrm{~mL}(5 \mathrm{mmol})$ styrene was added. The ratio of substrate to catalyst $(S / C)$ was controlled. For the gas-powder phase ethylene hydrogenation, $\mathrm{Pd} / \mathrm{Al}_{2} \mathrm{O}_{3}$ was first reduced at $100^{\circ} \mathrm{C}$ for $30 \mathrm{~min}$ before cooled down to $30^{\circ} \mathrm{C}$ and applied in ethylene hydrogenation. For $\mathrm{CO}$ adsorption, the catalyst was treated with $5 \% \mathrm{CO} / \mathrm{Ar}$ $(30 \mathrm{~mL} / \mathrm{min})$ at $30^{\circ} \mathrm{C}$ for $15 \mathrm{~min}$, then flushed with feed gas at $60^{\circ} \mathrm{C}$ for $30 \mathrm{~min}$ before cooled down to $30^{\circ} \mathrm{C}$. For CO desorption, the catalyst was treated with feed gas at $150^{\circ} \mathrm{C}$ for $30 \mathrm{~min}$, then cooled down to $30^{\circ} \mathrm{C}$ again. The production of $\mathrm{H}_{2} \mathrm{O}_{2}$ was performed following the procedure reported in the literature [45].

\section{Data Availability}

The data is available from the authors.

\section{Conflicts of Interest}

The authors declare that there is no conflict of interest regarding the publication of this article.

\section{Authors' Contributions}

R. Qin performed most of the experiments; P. Wang performed the DFT calculations; R. Qin and P. Wang wrote the original draft and contributed equally to this work. P. Liu, S. Mo, Y. Gong, L. Ren, C. Xu, K. Liu, and L. Gu supported this work in formal analysis and investigation. $\mathrm{N}$. Zheng and G. Fu were the project supervisors.

\section{Acknowledgments}

We thank the National Key R\&D Program of China (2017YFA0207304 and 2017YFA0207303), the NNSF of China (21890752, 21731005, 21721001, 21573178, and 91845102), and the Fundamental Research Funds for the Central Universities (20720180026) for financial support. We thank the XAFS station (BL14W1) of the Shanghai Synchrotron Radiation Facility (SSRF).

\section{Supplementary Materials}

Supplemental information includes materials, additional experimental and theoretical methods, 41 figures, and 8 tables. Figure S1: optimized structure of anatase $\mathrm{TiO}_{2}(010)$ surface. Figure S2: optimized structure of $\mathrm{Pd}_{2} / \mathrm{TiO}_{2}, \mathrm{Pd}_{2} \mathrm{CO} /$ $\mathrm{TiO}_{2}, \mathrm{Pd}_{3} / \mathrm{TiO}_{2}$, and $\mathrm{Pd}_{3} \mathrm{CO} / \mathrm{TiO}_{2}$. Figure S3: optimized structure of $\mathrm{Pd}_{4} / \mathrm{TiO}_{2}$ and $\mathrm{Pd}_{7} / \mathrm{TiO}_{2}$. Figure S4: TS structures 
of $\mathrm{Pd}_{2} / \mathrm{TiO}_{2}$ and $\mathrm{Pd}_{2} \mathrm{CO} / \mathrm{TiO}_{2}$-catalyzed styrene hydrogenation. Figure S5: reaction pathway for styrene hydrogenation on $\mathrm{Pd}_{3} / \mathrm{TiO}_{2}$ and $\mathrm{Pd}_{3} \mathrm{CO} / \mathrm{TiO}_{2}$. Figure S6: TS structures of $\mathrm{Pd}_{3} / \mathrm{TiO}_{2}$ and $\mathrm{Pd}_{3} \mathrm{CO} / \mathrm{TiO}_{2}$-catalyzed styrene hydrogenation. Figure S7: the optimized structures of $2 \mathrm{H}$ adsorption and coadsorption of $\mathrm{CO}$ and $2 \mathrm{H}$ on $\mathrm{Pd}(100)$ and $\mathrm{Pd}(111)$ surfaces. Figure S8: the optimized structures of Pd clusters with coadsorption of $\mathrm{CO}$ and $2 \mathrm{H}$. Figure S9: the optimized structures of $2 \mathrm{H}$ adsorption and coadsorption of $\mathrm{CO}$ and $2 \mathrm{H}$ on $\mathrm{Pd}_{4} / \mathrm{TiO}_{2}$ and $\mathrm{Pd}_{7} / \mathrm{TiO}_{2}$. Figure $\mathrm{S} 10$ : TS structures for $\mathrm{H}_{2}$ dissociation on $\mathrm{Pd}_{2} \mathrm{CO} / \mathrm{TiO}_{2}$ and $\mathrm{Pd}_{3} \mathrm{CO} / \mathrm{TiO}_{2}$. Figure $\mathrm{S} 11$ : structures and adsorption energies of styrene on $\mathrm{Pd}_{2} \mathrm{CO} /$ $\mathrm{TiO}_{2}$ and $\mathrm{Pd}_{2} / \mathrm{TiO}_{2}$. Figure S12: the TEM images of $\mathrm{TiO}_{2}-$ EG and $\mathrm{TiO}_{2}$. Figure S13: the $\mathrm{N}_{2}$ adsorption/desorption isotherm of the $\mathrm{TiO}_{2}$ and the XRD patterns of $\mathrm{TiO}_{2}$ before and after $\mathrm{Pd}_{2} \mathrm{CO}$ cluster deposition. Figure S14: the zeta potential and thermogravimetric analysis (TGA) of $\mathrm{TiO}_{2}$. Figure S15: the X-band EPR spectrum of the as-obtained $\mathrm{TiO}_{2}$ and $\mathrm{Pd}_{2} \mathrm{CO} / \mathrm{TiO}_{2}$. Figure S16: low-magnification HAADF-STEM image and corresponding EDX element mapping of $\mathrm{Pd}_{2} \mathrm{CO} / \mathrm{TiO}_{2}$. Figure S17: HRTEM images of $\mathrm{Pd}_{2} \mathrm{CO} / \mathrm{TiO}_{2}$. Figure S18: UV-vis spectrum of the $\mathrm{Pd}_{2} \mathrm{CO}$ cluster and $\mathrm{TiO}_{2}$ powder before and after loading the $\mathrm{Pd}_{2} \mathrm{CO}$ cluster. Figure S19: HAADF-STEM images of $\mathrm{Pd}_{2} \mathrm{CO} / \mathrm{TiO}_{2}$. Figure S20: the unit cell structure of $\left(\mathrm{PPh}_{4}\right)_{2}\left[\mathrm{Pd}_{2}(\mu-\right.$ $\mathrm{CO})_{2} \mathrm{Cl}_{4}$. Figure S21: the Pd K-edge XAS and XANES. Figure S22: EXAFS fitting of Pd foil, $\left(\mathrm{PPh}_{4}\right)_{2}\left[\mathrm{Pd}_{2}(\mu-\mathrm{CO})_{2} \mathrm{Cl}_{4}\right]$ and $\mathrm{Pd}_{2} \mathrm{CO} / \mathrm{TiO}_{2}$. Figure S23: Releasing of $\mathrm{CO}_{2}$ upon adding $\mathrm{TiO}_{2}$ to the solution of $\mathrm{H}_{2}\left[\mathrm{Pd}_{2}(\mu-\mathrm{CO})_{2} \mathrm{Cl}_{4}\right]$. Figure S24: CODRIFTS of the as-obtained $\mathrm{Pd}_{2} \mathrm{CO} / \mathrm{TiO}_{2}$. Figure S25: TPDMS signal of $\mathrm{CO}$ for blank $\mathrm{TiO}_{2}$ and the as-obtained $\mathrm{Pd}_{2} \mathrm{CO} /$ $\mathrm{TiO}_{2}$. Figure S26: in situ DRIFTS for $\mathrm{Pd}_{2} \mathrm{CO} / \mathrm{TiO}_{2}$ in ethylene hydrogenation. Figure S27: the mass-specific activity and TOF of styrene hydrogenation catalyzed by different Pd catalysts. Figure S28: isotopic experiment of $\mathrm{Pd}_{2} \mathrm{CO} / \mathrm{TiO}_{2}$-catalyzed styrene hydrogenation. Figure S29: EXAFS fitting of $\mathrm{Pd}_{2} \mathrm{CO} / \mathrm{TiO}_{2}$ after styrene hydrogenation. Figure S30: catalytic performance of $\mathrm{Pd}_{2} \mathrm{CO} / \mathrm{TiO}_{2}$ in five test rounds. Figure S31: DRIFT spectrum of $\mathrm{Pd}_{2} / \mathrm{TiO}_{2}$-cal before and after treatment with CO. Figure S32: XANES and EXAFS fitting of $\mathrm{Pd}_{2} / \mathrm{TiO}_{2}$-cal after treatment with $\mathrm{H}_{2}$ and further with $\mathrm{CO}$. Figure S33: catalytic performance and Arrhenius plot of $\mathrm{Pd}_{2} / \mathrm{TiO}_{2}$-cal-catalyzed styrene hydrogenation. Figure S34: catalytic styrene hydrogenation performance of $\mathrm{Pd}_{1} / \mathrm{TiO}_{2}$ cal and Pd cube with or without CO. Figure S35: the XRD pattern and $\mathrm{N}_{2}$ adsorption/desorption isotherm profile of $\gamma-\mathrm{Al}_{2} \mathrm{O}_{3}$. Figure S36: TEM images of $0.5 \mathrm{wt} \% \mathrm{Pd} / \mathrm{Al}_{2} \mathrm{O}_{3}$. Figure $337: \mathrm{H}_{2}$ TPD, $\mathrm{CO}$ TPD, and $\mathrm{H}_{2}$ TPD with preadsorbed $\mathrm{CO}$ over $0.5 \mathrm{wt} \% \mathrm{Pd} / \mathrm{Al}_{2} \mathrm{O}_{3}$. Figure S38: the in situ CODRIFTS for $0.5 \mathrm{wt} \% \mathrm{Pd} / \mathrm{Al}_{2} \mathrm{O}_{3}$. Figure S39: TEM images of $0.2 \mathrm{wt} \% \mathrm{Pd}_{2} \mathrm{CO} / \mathrm{Al}_{2} \mathrm{O}_{3}$. Figure S40: EXAFS fitting of $\mathrm{Pd}_{2} \mathrm{CO} / \mathrm{Al}_{2} \mathrm{O}_{3}$. Figure $\mathrm{S} 41$ : styrene hydrogenation catalyzed by $0.2 \mathrm{wt} \% \mathrm{Pd}_{2} \mathrm{CO} / \mathrm{Al}_{2} \mathrm{O}_{3}$. Table S1: adsorption energies of $2 \mathrm{H}\left(\Delta E_{2 \mathrm{H}}\right)$ for $\mathrm{Pd}_{n}$ clusters on the $\mathrm{TiO}_{2}(010)$ surface in the absence or in the presence of CO. Table S2: the Pd-Pd distances in $\mathrm{Pd}_{n}$ and $\mathrm{Pd}_{n} \mathrm{CO}$ clusters on $\mathrm{TiO}_{2}(010)$ and the bare clusters. Table S3: the total magnetizations of $\mathrm{Pd}$ in $\mathrm{Pd}_{n}$ and $\mathrm{Pd}_{n} \mathrm{CO}$ clusters on $\mathrm{TiO}_{2}(010)$ and the bare clusters. Table S4: the average bader charges of $\mathrm{Pd}$ in $\mathrm{Pd}_{n}$ and $\mathrm{Pd}_{n} \mathrm{CO}$ clusters on $\mathrm{TiO}_{2}(010)$. Table S5: crystal data and structure refinement for $\left(\mathrm{Ph}_{4} \mathrm{P}\right)_{2}\left[\mathrm{Pd}_{2}(\mu-\mathrm{CO})_{2} \mathrm{Cl}_{4}\right]$. Table S6: atomic coordinates and equivalent isotropic displacement parameters for $\left(\mathrm{Ph}_{4} \mathrm{P}\right)_{2}\left[\mathrm{Pd}_{2}(\mu-\mathrm{CO})_{2} \mathrm{Cl}_{4}\right]$. Table S7: EXAFS fitting results. Table S8: production efficiency of the $\mathrm{H}_{2} \mathrm{O}_{2}$ following the 2eAQ hydrogenation route catalyzed by different catalysts reported. (Supplementary Materials)

\section{References}

[1] L. Liu and A. Corma, "Metal catalysts for heterogeneous catalysis: from single atoms to nanoclusters and nanoparticles," Chemical Reviews, vol. 118, no. 10, pp. 4981-5079, 2018.

[2] E. Roduner, "Size matters: why nanomaterials are different," Chemical Society Reviews, vol. 35, no. 7, pp. 583-592, 2006.

[3] F. Yang, D. H. Deng, X. L. Pan, Q. Fu, and X. H. Bao, "Understanding nano effects in catalysis," National Science Review, vol. 2, no. 2, pp. 183-201, 2015.

[4] X. F. Yang, A. Wang, B. Qiao, J. Li, J. Liu, and T. Zhang, "Single-atom catalysts: a new frontier in heterogeneous catalysis," Accounts of Chemical Research, vol. 46, no. 8, pp. 1740-1748, 2013.

[5] M. Flytzani-Stephanopoulos and B. C. Gates, "Atomically dispersed supported metal catalysts," Annual Review of Chemical and Biomolecular Engineering, vol. 3, no. 1, pp. 545-574, 2012.

[6] M. G. Evans and M. Polanyi, "Inertia and driving force of chemical reactions," Transactions of the Faraday Society, vol. 34, pp. 11-24, 1938.

[7] T. Bligaard, J. K. Nørskov, S. Dahl, J. Matthiesen, C. H. Christensen, and J. Sehested, "The Brønsted-Evans-Polanyi relation and the volcano curve in heterogeneous catalysis," Journal of Catalysis, vol. 224, no. 1, pp. 206-217, 2004.

[8] A. Logadottir, T. H. Rod, J. K. Nørskov, B. Hammer, S. Dahl, and C. J. H. Jacobsen, "The Brønsted-Evans-Polanyi Relation and the Volcano Plot for Ammonia Synthesis over Transition Metal Catalysts," Journal of Catalysis, vol. 197, no. 2, pp. 229231, 2001.

[9] C. Dong, C. Lian, S. Hu et al., "Size-dependent activity and selectivity of carbon dioxide photocatalytic reduction over platinum nanoparticles," Nature Communications, vol. 9, no. 1, article 1252, 2018.

[10] J. Zheng, S. Y. Zhou, S. Gu, B. J. Xu, and Y. S. Yan, "Sizedependent hydrogen oxidation and evolution activities on supported palladium nanoparticles in acid and base," Journal of the Electrochemical Society, vol. 163, no. 6, pp. F499-F506, 2016.

[11] E. Roduner, "Understanding catalysis," Chemical Society Reviews, vol. 43, no. 24, pp. 8226-8239, 2014.

[12] M. S. Chen and D. W. Goodman, "The structure of catalytically active gold on titania," Science, vol. 306, no. 5694, pp. 252-255, 2004.

[13] K. Honkala, A. Hellman, I. N. Remediakis et al., "Ammonia synthesis from first-principles calculations," Science, vol. 307, no. 5709, pp. 555-558, 2005.

[14] M. Valden, X. Lai, and D. W. Goodman, "Onset of catalytic activity of gold clusters on titania with the appearance of nonmetallic properties," Science, vol. 281, no. 5383, pp. 1647-1650, 1998.

[15] S. H. Joo, J. Y. Park, J. R. Renzas, D. R. Butcher, W. Huang, and G. A. Somorjai, "Size effect of ruthenium nanoparticles in 
catalytic carbon monoxide oxidation," Nano Letters, vol. 10, no. 7, pp. 2709-2713, 2010.

[16] I. V. Yudanov, A. Genest, S. Schauermann, H. J. Freund, and N. Rosch, "Size dependence of the adsorption energy of CO on metal nanoparticles: a DFT search for the minimum value," Nano Letters, vol. 12, no. 4, pp. 2134-2139, 2012.

[17] P. Rodriguez, Y. Kwon, and M. T. Koper, "The promoting effect of adsorbed carbon monoxide on the oxidation of alcohols on a gold catalyst," Nature Chemistry, vol. 4, no. 3, pp. 177-182, 2011.

[18] T. Zhang, Z. P. Liu, S. M. Driver, S. J. Pratt, S. J. Jenkins, and D. A. King, "Stabilizing CO on Au withNO2: electronegative species as promoters on coinage metals?," Physical Review Letters, vol. 95, no. 26, article 266102, 2005.

[19] P. Wang, S. N. Steinmann, G. Fu, C. Michel, and P. Sautet, "Key role of anionic doping for $\mathrm{H} 2$ production from formic acid on Pd(111)," ACS Catalysis, vol. 7, no. 3, pp. 1955-1959, 2017.

[20] H. C. Kwon, M. Kim, J. P. Grote et al., "Carbon monoxide as a promoter of atomically dispersed platinum catalyst in electrochemical hydrogen evolution reaction," Journal of the American Chemical Society, vol. 140, no. 47, pp. 16198-16205, 2018.

[21] N. López, B. Bridier, and J. Pérez-Ramírez, "Discriminating reasons for selectivity enhancement of CO in alkyne hydrogenation on palladium," Journal of Physical Chemistry C, vol. 112, no. 25, pp. 9346-9350, 2008.

[22] G. Chen, C. Xu, X. Huang et al., "Interfacial electronic effects control the reaction selectivity of platinum catalysts," Nature Materials, vol. 15, no. 5, pp. 564-569, 2016.

[23] P. Liu, R. Qin, G. Fu, and N. Zheng, "Surface coordination chemistry of metal nanomaterials," Journal of the American Chemical Society, vol. 139, no. 6, pp. 2122-2131, 2017.

[24] F. Studt, F. Abild-Pedersen, T. Bligaard, R. Z. Sorensen, C. H. Christensen, and J. K. Norskov, "Identification of nonprecious metal alloy catalysts for selective hydrogenation of acetylene," Science, vol. 320, no. 5881, pp. 1320-1322, 2008.

[25] V. Pallassana and M. Neurock, "Electronic factors governing ethylene hydrogenation and dehydrogenation activity of pseudomorphic PdML/Re (0001), PdML/Ru (0001), Pd (111), and PdML/Au (111) surfaces," Journal of Catalysis, vol. 191, no. 2, pp. 301-317, 2000.

[26] M. P. Humbert and J. G. Chen, "Correlating hydrogenation activity with binding energies of hydrogen and cyclohexene on $\mathrm{M} / \mathrm{Pt}(111)(\mathrm{M}=\mathrm{Fe}, \mathrm{Co}, \mathrm{Ni}, \mathrm{Cu})$ bimetallic surfaces," Journal of Catalysis, vol. 257, no. 2, pp. 297-306, 2008.

[27] X. Zhao, Y. Zhao, G. Fu, and N. Zheng, "Origin of the facet dependence in the hydrogenation catalysis of olefins: experiment and theory," Chemical Communications, vol. 51, no. 60 , pp. 12016-12019, 2015.

[28] L. Y. Zhou, Y. Zhao, Z. N. Chen, G. Fu, and H. L. Wan, "The origin of the site preference of $\mathrm{H}$ adsorption on Pd (100)," Science China Chemistry, vol. 58, no. 1, pp. 156-161, 2015.

[29] X. Zhao, L. Zhou, W. Zhang et al., "Thiol treatment creates selective palladium catalysts for semihydrogenation of internal alkynes," Chem, vol. 4, no. 5, pp. 1080-1091, 2018.

[30] F. Zaera, "The surface chemistry of metal-based hydrogenation catalysis," ACS Catalysis, vol. 7, no. 8, pp. 4947-4967, 2017.

[31] L. Hung-Wen and C. Chun-Ming, "Size effect of Pd clusters on hydrogen adsorption," Journal of Physics: Condensed Matter, vol. 23 , no. 4 , article $045503,2011$.
[32] S. Y. Huang, C. D. Huang, B. T. Chang, and C. T. Yeh, "Chemical activity of palladium clusters: sorption of hydrogen," The Journal of Physical Chemistry B, vol. 110, no. 43, pp. 2178321787, 2006.

[33] M. Yang, J. Liu, S. Lee et al., “A common single-site Pt (II)-O $(\mathrm{OH})_{x^{-}}$species stabilized by sodium on "active" and "inert" supports catalyzes the water-gas shift reaction," Journal of the American Chemical Society, vol. 137, no. 10, pp. 34703473, 2015.

[34] S. X. Fei, B. Han, Q. F. Zhang, M. Yang, and H. S. Cheng, "Density functional theory study on the role of polyacetylene as a promoter in selective hydrogenation of styrene on a $\mathrm{Pd}$ catalyst," Journal of Physical Chemistry C, vol. 121, no. 8, pp. 4246-4252, 2017.

[35] L. Zhang, Y. Jia, G. Gao et al., "Graphene defects trap atomic $\mathrm{Ni}$ species for hydrogen and oxygen evolution reactions," Chem, vol. 4, no. 2, pp. 285-297, 2018.

[36] Y. Jia, L. Zhang, G. Gao et al., "A heterostructure coupling of exfoliated $\mathrm{Ni}-\mathrm{Fe}$ hydroxide nanosheet and defective graphene as a bifunctional electrocatalyst for overall water splitting," Advanced Materials, vol. 29, no. 17, article 1700017, 2017.

[37] X. Yan, Y. Jia, J. Chen, Z. Zhu, and X. Yao, "Defective-activated-carbon-supported $\mathrm{Mn}$-Co nanoparticles as a highly efficient electrocatalyst for oxygen reduction," Advanced Materials, vol. 28, no. 39, pp. 8771-8778, 2016.

[38] F. Studt, F. Abild-Pedersen, T. Bligaard, R. . Z. Sørensen, C. . H. Christensen, and J. . K. Nørskov, "On the role of surface modifications of palladium catalysts in the selective hydrogenation of acetylene," Angewandte Chemie, International Edition, vol. 47, no. 48, pp. 9299-9302, 2008.

[39] S. S. Sung and R. Hoffmann, "How carbon monoxide bonds to metal surfaces," Journal of the American Chemical Society, vol. 107, no. 3, pp. 578-584, 1985.

[40] P. Hu, D. A. King, M. H. Lee, and M. C. Payne, "Orbital mixing in Co chemisorption on transition-metal surfaces," Chemical Physics Letters, vol. 246, no. 1-2, pp. 73-78, 1995.

[41] H. Li, G. Chen, H. Yang et al., "Shape-controlled synthesis of surface-clean ultrathin palladium nanosheets by simply mixing a dinuclear PdIcarbonyl chloride complex with $\mathrm{H}_{2} \mathrm{O}$," Angewandte Chemie, International Edition, vol. 125, no. 32, pp. 8526-8530, 2013.

[42] P. L. Goggin, R. J. Goodfellow, I. R. Herbert, and A. G. Orpen, "Bridging by carbonyl $v s$. halide ligands: $X$-ray crystal structure of $\left[\mathrm{NBu}_{4}{ }^{\mathrm{n}}\right]_{2}\left[\mathrm{Pd}_{2} \mathrm{Cl}_{4}(\mu-\mathrm{CO})_{2}\right]$," Journal of the Chemical Society, Chemical Communications, vol. 20, pp. 1077-1079, 1981.

[43] S. Liu, J. M. Tan, A. Gulec et al., "Direct synthesis of lowcoordinate Pd catalysts supported on SiO2via surface organometallic chemistry," ACS Catalysis, vol. 6, no. 12, pp. 8380 8388, 2016.

[44] P. Liu, Y. Zhao, R. Qin et al., "A vicinal effect for promoting catalysis of $\mathrm{Pd}_{1} / \mathrm{TiO}_{2}$ : supports of atomically dispersed catalysts play more roles than simply serving as ligands," Scientific Bulletin, vol. 63, no. 11, pp. 675-682, 2018.

[45] M. D. Rossell, F. J. Caparrós, I. Angurell et al., "Magnetite-supported palladium single-atoms do not catalyse the hydrogenation of alkenes but small clusters do," Catalysis Science \& Technology, vol. 6, no. 12, pp. 4081-4085, 2016.

[46] K. Liu, R. Qin, L. Zhou et al., " $\mathrm{Cu}_{2} \mathrm{O}$-supported atomically dispersed Pd catalysts for semihydrogenation of terminal alkynes: critical role of oxide supports," CCS Chemistry, vol. 1, no. 2, pp. 207-214, 2019. 
[47] Y. Lu, J. Wang, L. Yu et al., "Identification of the active complex for $\mathrm{CO}$ oxidation over single-atom Ir-on- $\mathrm{MgAl}_{2} \mathrm{O}_{4}$ catalysts," Nature Catalysis, vol. 2, no. 2, pp. 149-156, 2019.

[48] Y. Dai, X. Mu, Y. Tan et al., "Carbon monoxide-assisted synthesis of single-crystalline Pd tetrapod nanocrystals through hydride formation," Journal of the American Chemical Society, vol. 134, no. 16, pp. 7073-7080, 2012.

[49] G. Kresse and J. Hafner, "Ab initiomolecular dynamics for open-shell transition metals," Physical Review B, vol. 48, no. 17, pp. 13115-13118, 1993.

[50] G. Kresse and J. Furthmuller, "Efficient iterative schemes forab initiototal-energy calculations using a plane-wave basis set," Physical Review B, vol. 54, no. 16, pp. 11169-11186, 1996.

[51] J. P. Perdew, K. Burke, and M. Ernzerhof, "Generalized gradient approximation made simple [Phys. Rev. Lett. 77, 3865 (1996)]," Physical Review Letters, vol. 78, no. 7, pp. 13961396, 1997.

[52] G. Kresse and D. Joubert, "From ultrasoft pseudopotentials to the projector augmented-wave method," Physical Review B, vol. 59, no. 3, pp. 1758-1775, 1999.

[53] P. E. Blochl, "Projector augmented-wave method," Physical Review B, vol. 50, no. 24, pp. 17953-17979, 1994.

[54] G. Henkelman, B. P. Uberuaga, and H. Jonsson, "A climbing image nudged elastic band method for finding saddle points and minimum energy paths," The Journal of Chemical Physics, vol. 113, no. 22, pp. 9901-9904, 2000.

[55] V. Kumar and Y. Kawazoe, "Icosahedral growth, magnetic behavior, and adsorbate-induced metal-nonmetal transition in palladium clusters," Physical Review B, vol. 66, no. 14, article 144413, 2002.

[56] B. J. Morgan and G. W. Watson, "A DFT+U description of oxygen vacancies at the $\mathrm{TiO}_{2}$ rutile (110) surface," Surface Science, vol. 601, no. 21, pp. 5034-5041, 2007.

[57] J.-C. Liu, X.-L. Ma, Y. Li, Y. G. Wang, H. Xiao, and J. Li, "Heterogeneous $\mathrm{Fe}_{3}$ single-cluster catalyst for ammonia synthesis via an associative mechanism," Nature Communications, vol. 9, no. 1, article 1610, 2018.

[58] P. Liu, "Understanding the behavior of $\mathrm{TiO}_{2}(110)$-Supported $\mathrm{Pd}_{7}$ cluster: a density functional study," Journal of Physical Chemistry C, vol. 116, no. 48, pp. 25337-25343, 2012. 